\title{
Container Positivity and Larva Distribution Based on the Container Characteristics
}

\author{
Wanti $^{1}$, Ririh Yudhastuti ${ }^{2}$, Subagyo Yotopranoto ${ }^{3}$, Hari B. Notobroto ${ }^{4}$, Sri Subekti ${ }^{5}$, Sitti R. Umniati ${ }^{6}$ \\ 1,2,4 Faculty of Public Health, UNAIR, Surabaya, Indonesia \\ ${ }^{3}$ Faculty of Medicine, UNAIR, Surabaya, Indonesia \\ ${ }^{5}$ Faculty of Fisheries and Marine, UNAIR, Surabaya, Indonesia \\ ${ }^{6}$ Faculty of Medicine, UGM, Yogyakarta, Indonesia
}

\begin{tabular}{l} 
Article Info \\
\hline Article history: \\
Received Jul 11, 2017 \\
Revised Aug 16, 2017 \\
Accepted Aug 30, 2017 \\
\hline Keyword: \\
Container characteristic \\
Container positivity \\
Density \\
Larva and pupa
\end{tabular}

\begin{abstract}
Dengue Haemorrhagic Fever (DHF) prevention and control program has been conducted in Kupang City but DHF Incidence Rate (IR) is always high and exceeds the national average. Calculating the density of larvae and pupae is a good choice in calculating DHF mosquitos' density because larvae capture is easier than mosquitoes, and pupa is the nearest stage with adult mosquitoes so can better represent actual mosquito density. This observational study used cross sectional study design was conducted in Kupang City as many 24 urban villages or 480 houses during the rainy and dry season and all containers inside and outside homes selected been observed. Larvae and pupae were collected using gamadotik then identified. Analyzed data were using multiple regression logistic test, independent $t$ test and Anova test. This study found 781 containers with the equation model of container positivity $=2,975$ lid -0.192 material +0.781 type $-3,706$, with the most influential variable is the container lid (OR 19.5). Ae. Aegypti, Ae. Albopictus and Culex can be found in water containers both inside and outside homes. The presence of larvae can be prevented either by doing closed and drain the container regularly and bury or drying container that is not used anymore. As limitation of water supply so other solutions need to be taken such as by sprinkling temefos into container with closed tightly to reduce the container positivity 19.5 times. For greater container can be done by water draining or reuse used container outside the home into a place to plant flowers or plants or become temporary garbage.
\end{abstract}

Copyright $\odot 2017$ Institute of Advanced Engineering and Science. All rights reserved.

\section{Corresponding Author:}

Wanti,

Faculty of Public Health,

UNAIR, Surabaya, Indonesia.

Email: trivena78@yahoo.com

\section{INTRODUCTION}

Dengue Haemorrhagic Fever (DHF) is a vector borne disease that contributes to disease burden, high mortality, poverty and social burden in the tropics and many days lost due to DHF each year [1]-[5]. As many as $70 \%$ of dengue cases worldwide live in Southeast Asia and the Western Pacific including in Indonesia [4]. DHF cases in Indonesia grew from 58 cases and 2 cities in 1968 to 100,347 and 433 cities / districts in 2014 [6]-[8].

Nusa Tenggara Timur (NTT) province including DHF endemic with Incidence Rate (IR) from 20002014 ranged from 0.6 to 37.1 cases per 100,000 population, and this figure is lower than national IR ranging from 10.2 to 71.8 cases per 100,000 population. This is in contrast to Kupang City as the capital of NTT province which IR from 1999-2015 ranged from 11.1 to 266.5 cases per 100,000 population and this IR is always the highest in NTT and also always higher than the national average. 
DHF prevention and control program has been conducted in Kupang City until 2015 with activities such as mosquito nest eradication, epidemiological investigation, abatization, focus fogging and counselling [9], but DHF IR is always high and exceeds the national average, and the larvae free rate are always low and do not follow the rainfall pattern [10]. Previous research has found that the percentage of water reservoirs in larval positive is greater in non-endemic areas than in dengue endemic areas [11], but that study was conducted only during the dry season so it is important to examine whether the season affects the presence of larvae and Pupa in water containers.

Calculating the density of larvae and pupae is a good choice in calculating DHF mosquitoes density because larvae capture is easier than mosquitoes, and pupae is the nearest stage with adult mosquitoes so pupa density can better represent actual mosquito density. Given the importance role of water container in the presence of Aedes sp, this study will analyze the effect of container characteritics on the container positivity (the presence of larvae and pupae in container) and analyze the difference of average mosquito larvae species based on container characteristics. Until now there is no proper medicine that can be used for dengue disease [12], so the knowledge about the density of larvae and pupae and risk factors will be very helpful in breaking the chain of transmission of DHF by predicting and depressing the larval density of larvae and pupae.

\section{METHOD}

This study was observational research using cross sectional study design. The study was conducted in 12 urban villages during the dry season and 12 urban villages during the rainy season that spread across 6 sub-districts in Kupang City, NTT Province. Each urban village took 20 homes to sample the research so that the total sample of the study was 480 houses. Samples for container are all containers in and out of homes in 20 houses in 24 selected urban villages. Figure 1 shows the tool for collecting larvae and pupae that named Gamadotik.

Independent variables in this research are container type (bathtub, drum, reservoir, dispenser, bucket, and tank profile), container location (outer and in house), container material (cement, iron, ceramic and plastic), container lid condition (open, semi-open and closed), container color (dark and light) and season (dry and rainy season), while the dependent variable is the presence of larvae and pupa in container (container positivity). The data obtained are primary data that is obtained by direct observation of container conditions conducted in the dry season and then the observations are repeated in the rainy season. In addition, all larvae and pupae in container in homes selected were collected using gamadotik ie tools for collection of all larvae and pupae made by Faculty of Medicine UGM. The larvae were then identified in the entomology laboratory using a larval identification guide [13].

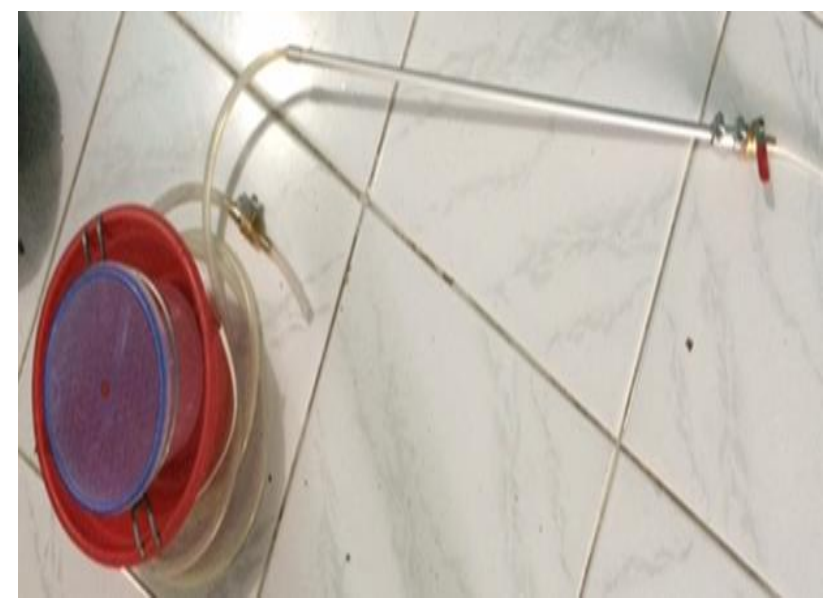

Figure 1. Gamadotik (Tool for collecting all larvae and pupae in container)

Data of container characteristic and container positivity were then presented in tabular form. All data including categorical data so were analyzed using multiple regression logistic test to make predictive model of container positivity. Distribution of larvae species were made in tabular form, then the difference of average number of larvae species in each container was tested by independent $t$ test and Anova test. 


\section{RESULTS}

\subsection{Results}

The univariate analysis showed that the higher container with larvae and pupae were found in drum, out-of-home container, iron-filled container, open or semi open lid container, dark-colored container and in the rainy season. Detailed distribution of container with larvae and pupa can be seen in Table 1 .

Table 1. The Relation of Container Positivity with The Research Variables

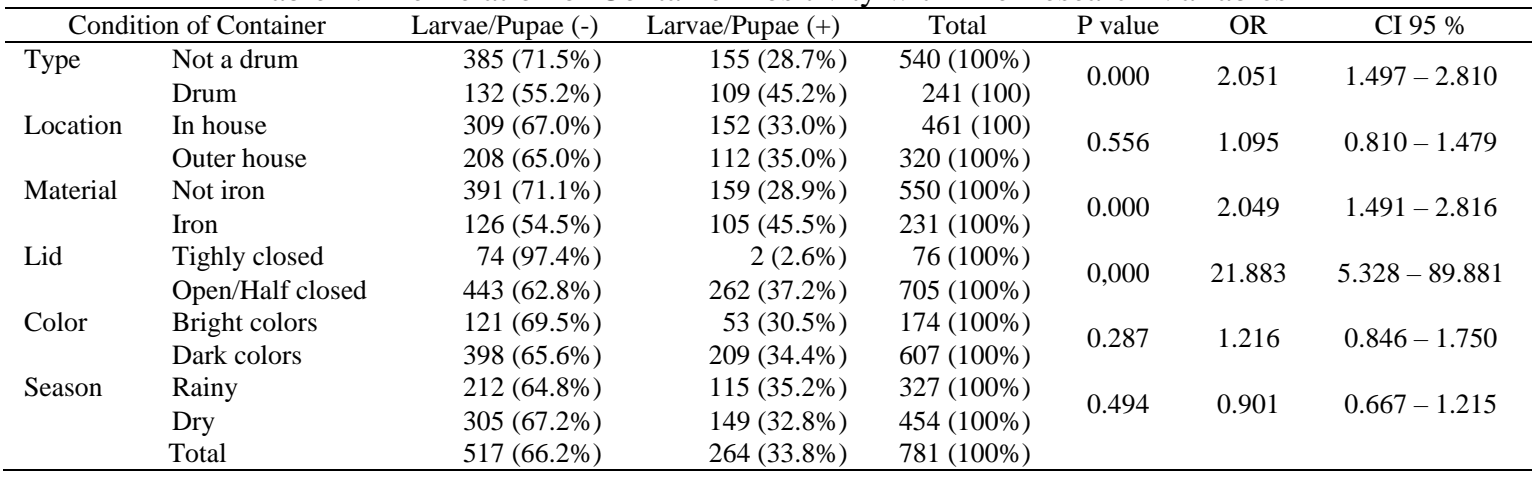

In bivariate analysis there were only 3 variables related to container positivity because it has p value $<0.25$ ie container type, container material and container cap. There are only three variables are included in multivariate analysis, as shown in Table 1.

The results of multivariate analysis showed that from 3 variables analyzed only one of $\mathrm{P}$ value $<0.05$ that is container lid condition, which type and container material have $\mathrm{p}$ value $>0.05$ so type and container material are excluded and starting from a higher $\mathrm{p}$ value and because there is a change of odd ratio (OR) $>10 \%$ so that the two variables are re-entered to obtain the final result as in Table 2.

Table 2. Multiple Reggresion Logistic Resulth of Research Variables

\begin{tabular}{lrrrrrrr}
\hline Variables in the Equation & \multicolumn{1}{c}{ B } & \multicolumn{1}{c}{ S.E. } & \multicolumn{1}{c}{ Wald } & Df & Sig. & Exp(B) & $95 \%$ CI \\
\hline Lid & 2.975 & 0.724 & 16.872 & 1 & 0.000 & 19.597 & $4.738-81.054$ \\
Material & -0.192 & 0.657 & 0.086 & 1 & 0.770 & 0.825 & $0.228-2.989$ \\
Type & 0.781 & 0.651 & 1.439 & 1 & 0.230 & 2.184 & $0.610-7.823$ \\
Constant & -3.706 & 0.720 & 26.499 & 1 & 0.000 & 0.025 & \\
\hline
\end{tabular}

Table 2 shows the model of the final equation: Container Positivity $=2,975$ lid container -0.192 container material +0.781 container type $-3,706$. The presence of larvae and pupae or container positivty influenced by three variables simultaneously equal to $66.2 \%$, meaning $33.8 \%$ of the existence of larvae and pupa influenced by the existence of other variables not examined in this study. The most influential variable in this research is the presence of container cap with OR 19.595 meant open or half closed container gives the possibility of a container for positive larvae and pupae 19.595 times larger than closed container.

This research also identifies larvae species and its distribution based on container characteristic. Not all larvae and pupae could be identified in this research, and most identified mosquitoes (96.4\%) are Aedes aegypti (Ae. Aegypti), while Ae.albopictus and Culex sp is only $1.2 \%$ and $2.3 \%$ respectively, as seen Table 3. Mostly Ae. Aegypti and Culex sp are found in bathtubs, while Ae.albopictus in drums. Anova test results show that there is an average difference of Larvae Ae. Aegypti between container that is between bathtub and tank profile with $\mathrm{p}$ value 0.0045 . Table 3 shows that Ae. Aegypti is more common in container in the house, while Ae. albopictus and Culex sp are commonly found in outside container. Based on independent t test there is no difference of average number of larvae Ae. Aegypti between container types with p value 0.49. As for the average Ae. Albopictus there is a difference between being located inside the house and outside the house with a $\mathrm{p}$ value of 0.05 . The average of Culex $s p$ larvae is also no different between containers with $\mathrm{p}$ value 0.25 .

Table 3 also shows that mosquito larvae are commonly found in the container of cement. Specifically Ae. Aegypti and Culex sp are found in the container of cement, while Ae. Albopictus and Culex are commonly found in iron material. Based on the Anova test, no difference average Ae. Aegypti larvae were found between different material with $\mathrm{p}$ value 0.08 . While the average larvae Ae. Albopictus there is a 
difference between the cement material and iron material with $\mathrm{p}$ value of 0.05 . The three species of mosquitoes are most commonly found in opened containers, whereas confined containers do not find any mosquito larvae except Ae Aegypti. Anova one way test obtained value 0.004 which means there is a difference in the average larvae Ae. Aegypti between closed and opened container, while the average difference for Ae. Albopictus and Culex sp based on the lid condition is not found. Species Ae. Aegypti and Ae. Albopictus are more common in the dry season, while Culex sp is more common in the rainy season. Based on the result of Independent $\mathrm{T}$ Test it is found that there is no difference of average of Ae. Aegypti larvae in the dry season and rainy with p value 0.381, while for the average larvae Ae. Albopictus and Culex $s p$ there is a difference between rainy season and dry season with $\mathrm{p}$ value of 0.05 and 0.017 .

Table 3. Distribution of Mosquito Larvae Species by Container Type

\begin{tabular}{|c|c|c|c|c|c|}
\hline \multicolumn{2}{|c|}{ Container } & \multirow{2}{*}{$\begin{array}{l}\text { Ae. aegypti } \\
8,908(60.9 \%)\end{array}$} & \multirow{2}{*}{$\frac{\text { Ae. albopictus }}{32(17.2 \%)}$} & \multirow{2}{*}{$\begin{array}{l}\text { Culex sp } \\
262(73.8 \%)\end{array}$} & \multirow{2}{*}{$\begin{array}{c}\text { Total } \\
9,202(60.6 \%)\end{array}$} \\
\hline \multirow{6}{*}{ Type } & Bathtub & & & & \\
\hline & Drum & $5,188(35.5 \%)$ & $152(81.7 \%)$ & $92(25.9 \%)$ & $5,432(35.8 \%)$ \\
\hline & Reservoir & $275(1.9 \%)$ & $3(1.6 \%)$ & $0(0.0 \%)$ & $278(1.8 \%)$ \\
\hline & Dispenser & $6(0.0 \%)$ & $0(0.0 \%)$ & $0(0.0 \%)$ & $6(0.0 \%)$ \\
\hline & Bucket & $256(1.7 \%)$ & $0(0.0 \%)$ & $0(0.0 \%)$ & $256(1.7 \%)$ \\
\hline & Profil tank & $0(0.0 \%)$ & $0(0.0 \%)$ & $0(0.0 \%)$ & $0(0.0 \%)$ \\
\hline \multirow[t]{2}{*}{ Location } & In house & $9,094(62.1 \%)$ & $32(17 \%)$ & $118(33.2 \%)$ & $9,244(60.9 \%)$ \\
\hline & Outer house & $5,539(37.9 \%)$ & $155(83 \%)$ & $236(66.8 \%)$ & $5,930(39 . \%)$ \\
\hline \multirow[t]{4}{*}{ Material } & Cement & $7281(49.8 \%)$ & $35(18.7 \%)$ & $131(37 \%)$ & $7447(49.1 \%)$ \\
\hline & Iron & $4997(34.1 \%)$ & $152(81.3 \%)$ & $71(20.1 \%)$ & $5220(34.4 \%)$ \\
\hline & Ceramic & $1454(9.9 \%)$ & $0(0 \%)$ & $24(6.8 \%)$ & $1478(9.7 \%)$ \\
\hline & Plastic & $901(6.2 \%)$ & $00 \%)$ & $128(36.2 \%)$ & $1029(6.8 \%)$ \\
\hline \multirow[t]{3}{*}{ Cover } & Opened & $12,113(82.8 \%)$ & $136(72.7 \%)$ & $239(67.5 \%)$ & $12,488(82.3 \%)$ \\
\hline & Half opened & $2,358(16.1 \%)$ & $51(27.3 \%)$ & $115(32.5 \%)$ & $2,524(16.6 \%)$ \\
\hline & Closed & $162(1.1 \%)$ & $0(0.0 \%)$ & $0(0.0 \%)$ & $162(1.1 \%)$ \\
\hline \multirow[t]{3}{*}{ Season } & Dry & $9,099(62.2 \%)$ & $187(100 \%)$ & $10(2.8 \%)$ & $9,296(61.3 \%)$ \\
\hline & Rainy & $5,534(37.8 \%)$ & $0(0.0 \%)$ & $344(97.2 \%)$ & $5,878(38.7 \%)$ \\
\hline & & $14.633(100 \%)$ & $187(100 \%)$ & $354(100 \%)$ & $15.174(100 \%)$ \\
\hline
\end{tabular}

\subsection{Discussion}

This research found that the larvae/pupae positive container was less than that of the negative larvae/pupae container with 33.8\% Container Index (CI) where the CI outdoors (35\%) was higher than inside the house (33\%). This CI number in Kupang City is similar to CI in Tammamaung Makasar Village which obtains CI of $32.6 \%$ [14], but this CI is higher than in Banjarbaru as a city that is also endemic to DHF (28\% $\mathrm{CI}$ ), and CI in the home is also higher in Kupang City than in Banjarbaru which is only $28.7 \%$, as well as CI drum container higher in Kupang City than in Banjarbaru which is only 29.4\% [15].

Seen from the CI, Kupang City is a high-risk area for Dengue transmission [15] because CI $\leq 10 \%$ means an area will be safe from the risk of Dengue transmission. The high CI shows the density of mosquitoes is also high and this of course will increase the risk of Dengue transmission in Kupang City, for it needs an equation model to predict the presence of larvae and pupae in a container. Of the 6 independent variables studied, it was found that when the bivariate analysis only got three variables that $\mathrm{p}$ value $<0.25$ so that only 3 variables can be included in multivariate analysis that is container type, container material and container lid. After multivariate analysis finally got the equation model:

\section{Container Positivity = 2,975 lid container -0.192 container material +0.781 container type $-3,706$}

The container positivity or the existence of larvae and pupae in container are influenced by three variables simultaneously equal to $66.5 \%$. The most influential variable is the presence of container cap with OR 19.6 or open or half closed container gives the possibility of a container for positive larvae and pupae 19.6 times larger than closed container. The equation model shows that $33.5 \%$ of the existance of larvae and pupae are influenced by other variables not examined in this research. Other variables include the frequency of water filling and water volume [16], or possibly other variables such as conductivity, total dissolved solids (TDS), alkalinity, salinity, turbidity and the water's calcium content in the landfill [16]. In addiction the condition of the water container as a breeding ground for Aedes sp mosquitoes and the quality of housing such as house spacing, lighting, and construction of buildings and the condition of house sanitation also play a role in providing breeding grounds and the presence of Aedes sp [13],[17],[18].

The study found the Aedes and Culex larvae distributed in baths and drums from cement, iron, ceramics and plastic both inside and outside the house with Ae Aegypti percentages 96.4\%, Ae. Albopictus 
$1.2 \%$ and Culex sp 2.3\%. Distinct distribution of Ae. Aegypti and Culex tritaeniorhynchus is the temperature, rainfall and topography of the region, whereas TDS and $\mathrm{pH}$ of water are not related to the existence of both species [19]. This is in contrast to previous theories that Aedes enjoys living in clear water, and Ae. Albopictus live outside the home in the garden and around the house [13]. Culex is also used to living in dirty stagnant water, but in this study Culex is also found in bathtubs and drums commonly used to accommodate clean water. Culex prefers to breed in dirty and stagnant water, but this study of Culex is also found in containers for daily necessities of bathrooms and drums, in which containers are also found Aedes. This is likely due to water limitations so that the bathroom and drum are rarely cleaned and the water tends to be dirtier than the more buckets that are easier to clean.

Recent research has found that Ae. Aegypti larvae can also live in contaminated water such as sewer water [20]. This study found the existence of Aedes and Culex in one container that is in the drum and bathtub both inside and outside because the possibility of water in the container is very dirty due to water limitations so rarely drained and there is also a drum and bathtub that is not used anymore but Still contains water so that both genera of mosquito larvae can still live and breed,

Ability Ae. aegypti to live in polluted water is also supported by previous research that mention $A e$. aegypti is most dead in taps water and more able to live in sewer water with total growth of larvae and pupae in sewer water of $5.33 \%$ compared to dug well water, rain water and taps water [20]. The existence of mirkoorganisme as a food source of larvae in sewer water is likely to support the high survival and larval growth rate so that on the second day the larvae can grow into pupae in sewer water [20].

Similarly, another research found that the ability of Aedes sp eggs to hatch and the ability of Aedes $s p$ larvae live on sewer water is higher than that of dug wells and taps water, however Aedes sp does not survive in water polluted with soapy water [21]. Previous research has also found a variety of species of mosquito larvae in a natural and artificial container that is Ae. Aegypti, Ae. Albopictus, Culex quenqefasciatus, Armigeres subalbarus, Toxorhynchites sp and Lutzia sp [22] and there explained that the larval density negatively associated with the conductivity and $\mathrm{pH}$. While another study explained the existence of larvae associated with temperature [23].

With the discovery of larvae of Aedes and Culex in container for daily need shows that should the high presence of larvae in these containers can be prevented either by doing 3M (Menguras, Menutup, Mengubur *English: drain, seal, bury) is closed and drain the container regularly and bury or drying container that is not used anymore. Keep in mind in the water drain should be done while brushing against the inner wall of the container so that the mosquito eggs that are attached can be loose and wasted along the flow of water. Kupang city has limited water supply so that the depletion of container activities can not be done on a regular action, so other solutions need to be taken, for example by sprinkling temefos into container coupled with tightly closing the landfill. It is also based on the results of this study which showed in Kupang City closed container is only $2.6 \%$ contained larvae and pupae while the the opened or half closed $36.9 \%$. The cover has OR of 19.4 so as to seal off will reduce the risk of the presence of larvae and pupae in the container by 19.4 times.

Container drum also has the percentage of positive larvae and pupae are greater than not drum with an $\mathrm{OR}$ of 2.2, which means when the drum no longer used as a water reservoir again or when the drum as a whole are firmly closed, it can reduce the risk of the presence of larvae and pupae in Kupang City 2.2 times than when the drum is still in use or still not closed tightly. In this study because the existing containers are motsly large so that if not used again it is not possible to burial but water draining or reuse used container can be a good choice to solve this problem, such as used drums used to be flower pots or trash can, used bath tub outside the home can also reused into a place to plant flowers or plants and become temporary garbage or fish pond.

\section{CONCLUSION}

The final equation model of Container Positivity $=2,975$ lid container -0.192 container material + 0.781 container type $-3,706$. The presence of larvae can be prevented either by doing closed and drain the container regularly and bury or drying container that is not used anymore. Keep in mind in the water drain should be done while brushing against the inner wall of the container so that the mosquito eggs that are attached can be loose and wasted along the flow of water. As limitation of water supply so that the depletion of container activities can not be done on a regular action, so other solutions need to be taken such as by sprinkling temefos into container coupled with tightly closing the container to reduce the risk of the presence of larvae and pupae in the container 19.6 times. It is also need to manage the drum by closed firmly or reused used drum to reduce the risk of the presence of larvae and pupae 2.2 times. For greater container like bath tub can be done by water draining or reuse used bath tub outside the home into a place to plant flowers or plants or become temporary garbage. 


\section{ACKNOWLEDGEMENTS}

Many thank to Ministry of Health Republic of Indonesia, Head Office of Health Polytehnic Kupang and Head of Environment Health School for the dmittion and support, thank to my mentor who always helping and guiding me to do this research. I also thank to the local government and community, thank for your acceptance and collaboration. Many thanks also I give to everyone who already supported me all the time with kindness and sincerity.

\section{REFERENCES}

[1] J. K. Young-Su, et al., "Larvacidal Activity of Brazillian Plants Again Aedes aegypti and Culex pipiens pallens (Diptera: Culicidae)," Agric Chem Biotechnol, vol. 45, pp. 131-134, 2002.

[2] P. Cattand, et al., "Tropical Diseases Lacking Adequate Control Measures: Dengue, Leismaniasis, and African Trypanosomiasis," Chapter 23, D. T. Jamison, et al., editor, "Disease Control Priorities in Developing Countries," Edisi 2, World Bank, Washington (DC), 2006.

[3] S. B. Halstead, "Dengue-Virus Mosquito Interactions," Ann Rev Entomol, vol. 53, pp. 273-291, 2008.

[4] WHO, "Dengue Guidelines for Diagnosis, Treatment, Prevention and Control," WHO, Geneva, 2009.

[5] K. M. Ali, et al., "Bioecology and Vectorial Capacity of Aedes Mosquitoes (Diptera: Culicidae) in Irinjalakuda Municipality, Kerala, India in Relation to Disease Transmission," Int. J. Curr. Res Acad Rev, vol/issue: 2(4), pp. 43-49, 2014.

[6] WHO-SEARO, "Prevention and Control for Dengue and Dengue Haemorrhagic Fever," WHO-SEARO Pub, New Delhi, 2001.

[7] Center for Epidemiological Data and Surveillance, "DBD in Indonesia Year 1969-2009," Bul Window Ind, vol. 2, pp. 1-14, 2010.

[8] Ministry of Health RI, "Indonesia Health Profile 2014," Ministry of Health RI, Jakarta, 2015.

[9] Kupang City Health Office, "Kupang City Health Profile 2015," Kupang City Health Office, Kupang, 2016.

[10] Kupang City Health Office, "Recapitulation of Data Surveillance of DHF Kupang City," Unpublished, Kupang, 2015.

[11] Wanti and M. Darman, "Containers and Larva Density of Aedes in Endemic and DHF-free Areas," J Pub Hlth, vol/issue: 9(2), pp. 171-178, 2014.

[12] S. Sukowati, "Problems of Dengue Hemorrhagic Fever Vector (DBD) and Control in Indonesia," Bul Window Epid, vol. 2, pp. 25-30, 2010.

[13] Ditjen PP \& PL, "Guidelines for Dengue Haemorrhagic Entomology Surveys and Key Identification of Aedes Mosquitoes," Ministry of Health RI, Jakarta, 2013.

[14] A. Baharuddin and Rahman, "Characteristics of Breeding Places and Aedes aegypti Larva Growth," J Hlth of Taduloko, vol/issue: 1(2), pp. 61-71, 2015.

[15] M. R. Ridha, et al., "The Relation of Environmental Condition and Container to the Existance of the Aedes aegypti Larvae in DHF Endemic Area in Banjarbaru," Jurnal Buski, vol/issue: 4(3), pp. 133 - 137, 2013.

[16] J. A. L. Jeffrey, et al., "Water Level Flux in Household Container in Vietnam -A Key Determinant of Aedes aegypti population Dynamics," Plos One, E39067, vol/issue: 7(7), pp. 1-6, 2012.

[17] H. Ishak and A. Abbas, "Analysis of Density Factor of Aedes aegypti larvae and and Endemicity of Dengue Hemorrhagic Fever in Bulukumba District, South Sulawesi," Proceedings of National Seminar on Moslem Day 2009 "Community Participation in Integrated Mosquito Control Program", Bogor, 2009.

[18] A. P. Djati and D. Widiastuti, "Several Environmental Factors Related with Endemicity Status od Dengue Haemorrhagic Fever," Hlth Sci Ind, vol/issue: 3(1), pp. 27-30, 2012.

[19] M. Naeem, et al., "Spatial Distribution Modeling of Stegomyia aegypti and Culex tritaeniorhynchus (Diptera: Culicidae) in AL-bahah Province, Kingdom of Saudi Arabia," Tropical Biomedicine, vol/issue: 33(2), pp. 295-310, 2016.

[20] Sayono, et al., "Growth of Aedes aegypti larvae on Contaminated Water," J of Pub Hlth Indones, vol/issue: 7(1), pp. $15-22,2011$.

[21] A. Jacob, et al., "Survival and Growth of Aedes sp on Different Types of Water Brood," Jurnal e-Biomedik (eBM), vol/issue: 2(3), pp. 1-5, 2014.

[22] R. Gopalakrishnan, et al., "Physucochemical Characteristics of Habitats in Relation to the Dengue ContainerBreeding Mosquitoes in Asom, India," J Vector Borne Dis, vol. 50, pp. 215 - 219, 2013.

[23] A. A. Arsunan and E. Ibrahim, "Analysis Relationship and Mapping of the Environmental Factors with the Existance of Mosquito Larvae Aedes aegypti in the Endemic Area of Dengue Fever, Makasar, Indonesia," Int. J. Curr. Res. Aca. Rev, vol/issue: 2(11), pp. 1-9, 2014. 